\title{
Discussion on the Reform of Physical Education in Colleges and Universities under the Background of Information Technology and Curriculum Integration
}

\author{
Linlin Li
}

School of Physical Education of Sichuan Agricultural University, China

Keywords: Colleges And Universities; Sports Teaching; Information Technology; Curriculum Integration.

\begin{abstract}
With the continuous development of education and teaching reform, most subjects in the teaching process are mainly focused on the cultivation of students' ability to use information technology. At the same time, most subjects also incorporate information technology into the assessment of students. The goal of this approach is to develop comprehensive talents with comprehensive development. In this environment, the college physical education teaching should conform to the change of the educational reform and change the traditional teaching mode, and combine the development of information technology and curriculum integration to optimize the teaching process. This paper analyzes and studies the present situation of physical education in Colleges and universities, and puts forward some suggestions according to the integration of information technology and curriculum integration.
\end{abstract}

\section{Introduction}

The integration of modern information technology and education teaching is the characteristics of the current education, and it is also an important manifestation of the process of education reform. Integrating modern information technology into the teaching process can not only change the traditional way of teaching content, but also change the way of teaching and students' acceptance of knowledge. With the rapid development of society, the society needs more complex talents. Physical education is an important subject in Colleges and universities, which should strengthen the integration of information technology, and truly realize the teaching objectives of College Physical Education in the education reform.

The integration of information technology and curriculum in College Physical Education Teaching

The present situation of information technology resources. College physical education teaching needs a strong information technology to do the support and protection. This includes: multimedia equipment, computer, image equipment, etc.. Of course, it is also can not be separated from the network resources, software technology and other non material resources. But there are less information equipments for PE teachers in Colleges and universities. Most of the courses are open to the stadium or the playground, and the majority of the classroom is the teaching content of the teaching. This makes some sports teachers even specialized offices, or specialized office computer equipment. In the school teaching software purchase is also very limited. Which makes the physical education teachers in Colleges and universities can not really use the network teaching resources in the course of teaching. Therefore, physical education teachers can only be based on the existing teaching resources for teaching, which is difficult to meet the teaching needs of physical education [1].

The level of information technology of College Physical Education Teachers. At present, the traditional methods are often used in Physical Education in Colleges and universities in China. In the course of teaching, the students should pay attention to improving the students' physical literacy and skills training, but the awareness of the use of information technology needs to be improved. With the 
rapid development of modern information technology, the teaching mode and the teaching method should also be adjusted according to the information technology. In the process of PE teaching, teachers' innovation spirit is often lack. The performance of teachers only pay attention to the students' grades, but not from the actual situation to look for the lack of teaching in the process [2]. Physical education teachers tend to focus on the interpretation and teaching of the content of teaching materials. Some teachers think that there is no direct relationship between the use of information technology and the sports practice skills, so they don't need to think of College PE teachers teaching by using the network information technology.

Present situation of physical education teaching method. At the present stage, the teaching content of physical education in Colleges and universities is mainly based on the two aspects of sports theory knowledge and sports technology. In the actual teaching, physical education teachers are still to explain the theoretical knowledge and the training of teaching model students to imitate the teaching based [3]. In the course of the study of physical education students lack the corresponding enthusiasm and initiative, which requires the physical education teachers to master enough sports, and be able to achieve the standard. Physical education teachers can make full use of the network teaching resources will be able to show students more standard sports action, and make more scientific and rational comprehensive explanation and demonstration. This requires teachers to have the ability to use the network information technology to improve and reform the teaching process of physical education.

\section{The significance of information technology and curriculum integration in College Physical Education}

Promote the teaching reform of Physical Education. Promoting the integration of information technology and physical education curriculum to promote the reform of physical education in Colleges and universities in china. The teachers in this process by means of information technology, and the use of network teaching resources, combined with the teaching content of the scientific and reasonable teaching practice so that students can give full play to their subjective initiative in the process of learning. Students to learn on the independence and autonomy to promote their comprehensive quality of the upgrade [4]. In the practice teaching, physical education teachers can use the network information technology to search more abundant teaching resources, and also can exercise the ability and level of teachers to use modern technology. In practice, physical education teachers also improve their knowledge system, so as to be able to truly develop the teaching model and teaching design. In the process of research and integration of the whole teaching process, the use of network information, integration and inspiration can not only improve the teaching methods, but also help students to broaden their horizons. The application of multimedia technology can make the teaching process break through the limitation of practice and space. At the same time, the college physical education curriculum and the current information technology fully integrated, for the students to bring a rich and colorful teaching process, can also stimulate students' interest in learning [5].

Enhance students' comprehensive quality. In the course of college teaching, the spread of course content is the focus of teaching, but the development of students' comprehensive quality can not be ignored. In the college physical education teaching, whether it is the content of the physical education curriculum itself or the students' ability of information technology, the need to focus on the development of physical education teachers. The integration of information technology and curriculum in college physical education can bring more colorful knowledge, and it can also bring students a wider understanding of information, select the amount of information space. This can promote the formation of students' thinking patterns, and make students informed, and training students' innovation spirit and innovation ability. In actual teaching, extensive use of network multimedia equipment not only can be formed with the teaching content of figure words sound shadow form, also can show these comprehensive sensory promote students about brain levels of the balanced development of [6]. Obviously, the integration of information technology and physical 
education curriculum can promote the development of students' comprehensive quality in college physical education.

\section{Application of information technology and curriculum integration in College Physical Education}

Promote the development of teachers' information technology ability. Teachers are an important participant in the teaching process, especially in the course of the integration of information technology and physical education curriculum in college physical education, teachers play an irreplaceable role. This requires the college physical education teachers should have a certain degree of the level of information technology. The PE teachers have the ability to use information technology, and have a full understanding of the important impact of information technology on the teaching process, and has the ability to carry out the integration of information technology and classroom teaching practice in teaching. Physical education teachers should continue to "self charge" in teaching ". For example, through continuous learning to improve the self. Physical education teachers can use information technology and constantly improve their ability to accept and use new technology, so that they can keep up with the pace of social science and technology development, thus promoting the modernization of education and teaching reform and development. In University, the relevant professional and technical knowledge should be introduced to the physical education teachers on a regular basis, and to organize the assessment to promote the mutual communication between the school physical education teachers and other campus physical education teachers. The school needs to introduce expert training for teachers, it can make an important role in promoting the development of teachers to their teaching skills level at the same time fully aware of the information technology in teaching, and truly grasp and use of information technology, and promote the upgrading of the level of teaching practice. Teachers in the learning process can not only fully draw lessons from advanced teaching mode, but also reflect on their own teaching process of the shortcomings and shortcomings of [7]. And the evaluation system of teachers in Colleges and universities can promote the improvement and development of the comprehensive quality of teachers' teaching level and the level of the application of information technology.

The integration of information technology and physical education teaching content. In sports teaching, teachers tend to ignore the real set of teaching content and information technology, which directly leads to the integration of information technology in the classroom can not play its due role in the integration of physical education. The current our country university physical education textbook version of numerous sports teachers, so the search and selection of network teaching resources should focus on its accuracy, pertinence and validity. At the same time, the individual differences between students can not be ignored. Teachers should also take into account their own level in the process of screening of the network teaching resources, and select related teaching resources, so as to achieve an objective to promote the sports teaching effectiveness promotion. The fundamental of physical education is to promote and develop students' practical skills. Colleges and universities sports classroom can use multimedia technology to show students sports action technology, etc.. This is for students to demonstrate and explain the correct, standardized sports. This can not only stimulate students' interest in learning, but also guarantee the professional and standardization of the transfer process of sports skills. At present, students in Colleges and universities are more flexible in their thinking, and they prefer to learn and understand the relevant activities in class. But at present our country university sports theory content is rich and colorful, therefore should try to choose the teaching content which has the pertinence and the interest. This is not only more in line with the characteristics of the students' interest, but also promote the improvement and development of teaching effectiveness.

Improve the infrastructure construction of basic information. Infrastructure construction is an important part of campus construction. In the information age, colleges should pay more attention to the construction and renewal of infrastructure related to information technology. Whether from the basic equipment or teaching software investment should increase the proportion of. Universities should first ensure that teachers are able to have enough access to more information technology. 
Multimedia facilities in the classroom can also be used as a platform and tool for teachers to use information technology. As a result of physical education teaching has certain teaching characteristics, so in the campus should be as far as possible to ensure that the teaching place in the network information coverage, at the same time to add multimedia facilities. At the same time, schools need to introduce more abundant network resources. This allows the combination of physical education teachers to screen, which can promote the development of physical education in Colleges and universities. For example: the construction of the school sports teaching website. Through the construction and development of these platforms, not only can meet the needs of the development of the comprehensive quality of teachers and students, but also meet the needs of the construction of modern campus. This also allows teachers in such a teaching environment for information technology to be truly integrated into the classroom teaching, while greatly enhancing the overall quality of students.

\section{Conclusion}

Visible, at this stage of China's education reform in the information technology to occupy an increasingly large proportion. The teaching reform of higher education should promote the integration of information technology into the teaching development, at the same time, ensure the teaching level of teachers and the improvement of students' learning quality. Especially the physical education teaching in Colleges and universities, compared with other subjects, the special characteristics. So we should take the integration measures targeted to promote the effectiveness and rationality of the integration. The process of the integration of information technology into physical education is very complex, which requires the physical education teachers in Colleges and universities to continue to study, explore and sum up experience in practice.

\section{Acknowledgement}

Funding project: this paper is funded by undergraduate thesis incubation programme of Sichuan Agricultural University.

\section{References}

[1] Xiong Xiaoyu. Analysis on the integration of information technology and curriculum in College Physical Education [J]. modern sports science and technology, 2015, 32 (04): 132-134.

[2] Liang Peigen. Strategies for effective integration of information technology and physical education curriculum in Colleges and universities [D]. Suzhou: Soochow University, 2013

[3] Peng Jing. Construction of information technology curriculum system for undergraduate physical education in sports colleges and universities in China [D]. Shanghai: Shanghai Institute of Physical Education, 2014

[4] Gao Gao. Problems and Countermeasures in the integration of information technology and physical education in Colleges and universities [J]. Journal of Shaanxi University of Technology (SOCIAL SCIENCE EDITION), 2014, 04 (02): 79-82.

[5] Zhou Wei. Research on the integration of digital physical education and curriculum in universities and colleges in China [D]. Sichuan: Sichuan University, 2014

[6] Li Ying, Li Pinyu. Discussion on the integrated teaching mode of information technology and physical education curriculum [J]. enterprise technology development, 2012, 07 (01): 149-163.

[7] Yuan Yihong, Song Jianhua, Jiang Kun. Modern information technology and the university sports teaching effective integration and development mode of the [J]. Journal of Jingdezhen college, 2013, 04 (02): 78-79. 